\title{
Combined Application of Chromosome Karyotype and Microarray Analysis in Fetus With Increased Nuchal Translucency
}

\author{
Wang Chaohong \\ Affiliated Maternity and Child Health Hospital of Anhui Medical University \\ Tang Junxiang \\ Affiliated Maternity and Child Health Hospital of Anhui Medical University \\ Sun Yuxiu \\ Affiliated Maternity and Child Health Hospital of Anhui Medical University \\ Pang Yu \\ Affiliated Maternity and Child Health Hospital of Anhui Medical University \\ Tong Keting \\ Affiliated Maternity and Child Health Hospital of Anhui Medical University \\ Zhu Jiansheng (D 593130772@qq.com) \\ Affiliated Maternity and Child Health Hospital of Anhui Medical University
}

\section{Research}

Keywords: nuchal translucency, Karyotype analysis, Microarray analysis

Posted Date: May 24th, 2021

DOI: https://doi.org/10.21203/rs.3.rs-524636/v1

License: (c) (1) This work is licensed under a Creative Commons Attribution 4.0 International License. Read Full License 


\section{Abstract}

ObjectiveXTo examine the risk of chromosomal abnormalities when the thickness of the nuchal translucency( NT) is $2.5-2.9 \mathrm{~mm}$, to evaluate the cutoff value of NT for prenatal diagnosis, to explore the value of combined application of chromosome karyotype and microarray analysis, and to explore the relationship between NT $\geq 5.0 \mathrm{~mm}$ and fetal prognosis.

Methods $₫ A$ total of 366 pregnant women who underwent prenatal diagnosis in Anhui Province Maternity and Child Health Hospital from January 2018 to August 2020 were collected, of which 241 cases had NT $\geq 2.5 \mathrm{~mm}, 125$ cases were elderly (35-38 years old) with NT $<2.5 \mathrm{~mm}$. We made grouping statistics on chromosome abnormalities, and compared the detection of chromosome abnormalities by karyotype and microarray analysis. At the same time, we followed up the fetuses with NT $\geq 5.0 \mathrm{~mm}$ and analyzed their prognosis.

Results: (1)Among the 366 cases with NT thickening,the detection rates of chromosome abnormalities by karyotype analysis and microarray analysis(CMA) were $13.39 \%$ (49/366) and 13.93\% (51/366), respectively, and there was no significant difference ( $P>0.05)$, including 25 cases of trisomy 21,5 cases of trisomy 18, 5 cases of Turner synthesis and 16 cases of other chromosome abnormalities. (2)We compared the effect of different NT value on the detection rate of pathogenic chromosomes, and found that the difference between NT $\geq 2.5 \mathrm{~mm}$ and $\mathrm{NT}<2.5 \mathrm{~mm}$ was statistically significant( $\mathrm{P}<0.05)$. The detection rates of pathogenic chromosomal abnormalities in NT < 2.5mm group,2.5-2.9mm group, 3.0-3.4mm group,3.5-4.4mm group,4.5-5.4mm group and NT $\geq$ $5.5 \mathrm{~mm}$ group were $0.8 \%(1 / 125), 11.63 \%(10 / 86), 17.81 \%(13 / 73), 20 \%(10 / 49), 47.62 \%(10 / 21)$ and $63.64 \%(7 / 11)$ respectively. (3)Our study found that different prenatal diagnostic indicators for abnormal chromosome detection rate difference was statistically significant $(P<0.05)$. The detection rates of NT thickening alone and NT thickening combined with other abnormalities were $13.17 \%(22 / 167)$ and $35.14 \%(26 / 74)$ respectively(P<0.05). (4)Among 18 pregnant women with NT $\geq 5.0 \mathrm{~mm}, 9$ fetuses were chromosomal abnormalities, and 9 fetuses survived healthily.

Conclusions $\triangle W$ When the NT value is $2.5-2.9 \mathrm{~mm}$, the incidence of fetal chromosome abnormality is significantly higher than that in the normal group. It is suggested that invasive prenatal diagnosis should be performed for pregnant women with NT $\geq 2.5 \mathrm{~mm}$. Chromosome karyotype analysis and CMA can complement each other, which is conducive to prenatal genetic counseling. The fetuses with NT thickening usually have good pregnancy outcomes when excluding fetal chromosome and prenatal ultrasound does not indicate any abnormalities.

\section{Background}

The nuchal translucency refers to the fetal neck subcutaneous echoless zone, namely the subcutaneous hydrops between fetal neck and skin [1]. According to statistics, about $5 \%$ of fetal NT measurements are greater than $95 \%$ percentile [2]. Fetal NT thickening in early pregnancy is closely related to adverse pregnancy outcomes such as chromosomal abnormalities [3], single genetic diseases [4] and fetal or perinatal death [5]. With the thickening of NT, the incidence of fetal chromosomal abnormalities also increases. When the NT value is greater than $6.5 \mathrm{~mm}$, the incidence of fetal chromosomal abnormalities is as high as $64.5 \%$ [6]. CMA is a high-resolution and high-throughput molecular detection technology for detecting human genomic DNA copy number variation, which can detect chromosomal microdeletions or microduplications that cannot be detected by karyotype analysis [7-9]. Studies have shown that CMA can increase the detection rates of chromosome abnormalities by $4 \%$ and $7 \%$ compared with the traditional karyotype analysis [10, 11]. At present, most studies have set the cutoff value of abnormal NT as 3.0-3.5 mm [12], and the application data of chromosome karyotype analysis and CMA in NT value of 2.5-2.9 $\mathrm{mm}$ are limited. Therefore, the purpose of this study is to examine the risk of chromosomal abnormalities in fetuses with NT value of 2.5-2.9, to evaluate the cutoff value of NT thickening for prenatal diagnosis, and to explore the value of combined application of chromosome karyotype and microarray analysis, and to explore the relationship between NT $\geq 5.0 \mathrm{~mm}$ and fetal prognosis.

\section{Methods}

\section{Subjects}

Within a 35-month period (January 2018 to October 2020), 365 pregnant women (age: 17 44 years old; gestational week: $16^{+5} \sim 24^{+1}$ ) were enrolled for the prenatal diagnosis using G-band karyotyping and CMA in the Anhui Maternal and Child Health Care Hospital. The cohort was stratified according to the NT measurement: $\leq 2.5 ; 2.5-2.9 ; 3.0-3.4 ; 3.5-4.4 ; 4.5-5.4 ; \geq 5.5 \mathrm{~mm}$ with/without structural malformations. Patients were stratified according to the NT measurement only. The study was carried out under the approvement by the Hospital Ethics Committee of the Anhui Maternal and Child Health Care Hospital. Informed written consents were obtained from all pregnant women who received karyotyping and CMA.

\section{Conventional G-banded cytogenetic analysis}

The tests were obtained by patient agreement with the knowledge. Under the guidance of ultrasound, High-risk pregnant women underwent interventional surgery, and amniotic fluid samples were collected for prenatal diagnosis. Following steps: inoculation, culture, G-banding and Lycra GSL-120 automatic karyotype scanner were followed to identify karyotypes. According to the principle of "An International System for Human Cytogenetic Nomenclature, ISCN2016", a total of 30 dividing phases were counted per sample, using an Al chromosome image analysis system (CytoVision, Switzerland), and 5 karyotypes were analyzed and double counts were obtained in case of mosaic.

\section{Chromosomal mlcroarray analysis (CMA)}

The amniotic fluid samples were centrifuged at $4{ }^{\circ} \mathrm{C}, 1,000 \mathrm{~g}$ for 10 minutes. Cell precipitation was retained to extract DNA samples. The absorbance of DNA samples (A260 / $280 \mathrm{~nm}$ ) was maintained at 1.7 1.9. DNA samples $(4 \mu \mathrm{L})$ were taken, and SNP array was detected according to the instructions of Humancyto SNP-12 BeadChip kits (Illumina, Santiago, USA). The data were collected by iSCAN scanning system, and the results were analyzed by GenomeStudio software.SNP-array 750K containing about 750,000 SNP probes. Chromosomal analysis is preformed with Affymetrix Chromosome Analysis 
Suite (ChAS) software. Data was visualized and analyzed by Chromosome Analysis Suite (ChAS) software package (Affymetrix, USA). Based on NCBI human genome build 37 (hg 19) to reported the CNVs.CNVs were evaluated through a filtering procedure and identified with five categories based on the ACMG guideline. Detected CNVs were evaluated based on the following public databases:DECIPHER,OMIM,etc. The detected CNVs were classified into five categories: pathogenic CNVs, benign CNVs, variants of uncertain significance (VOUS), likely pathogenic CNVs and likely benign CNVs. In current study, we only reported the pathogenic CNVs, likely pathogenic CNVs and VOUS.

\section{Statistical analysis}

Statistical analysis was performed with SPSS version 23 (SPSS Inc., Chicago, IL, USA). Comparisons between groups were performed by using chi-squared test. A $P$-value of $<0.05$ was considered as statistically significant.

\section{Results}

\section{Conventional karyotype analysis and CMA results}

Among the 366 samples, there were 241 cases with NT $\geq 2.5 \mathrm{~mm}$ and 125 cases with advanced age (35-38 years old) with NT < $2.5 \mathrm{~mm}$. The detection rates of chromosome abnormalities in karyotype analysis and CMA were $13.39 \% \varangle 49 / 366 \rrbracket$ and $13.93 \% \varangle 51 / 366 \rrbracket$, respectively, and the difference was not statistically significant $(P>0.05)$. Conventional karyotype analysis and CMA detected 48 cases of chromosomal abnormalities, including 25 cases of trisomy 21,5 cases of trisomy 18, 5 cases of Turner synthesis, and 13 cases of other chromosome abnormalities ( 2 cases of $47, \mathrm{XXX}, 3$ cases of $47, \mathrm{XXY}, 1$ case of $47, \mathrm{XYY} / 46$, $\mathrm{XY}, 1$ case of $47, \mathrm{XX},+$ mar, 6 cases of chromosome partial trisomy and monomer). In addition, one case of balanced translocation was only detected by routine karyotype analysis, and 3 cases of pathogenic copy number variation (CNVs), 2 cases of likely pathogenic CNVs and 15 cases of unknown significance ( VOUS ) variation were only detected by CMA (Table 1). We classified all CNVs and followed up the pregnancy (Table 2). Among them, 5 cases had chromosome microdeletion and microduplication, 3 cases were verified by their parents, 2 cases had new variation, and 1 case was caused by balanced translocation heredity (figure 1).

\section{Comparison of fetal chromosomal abnormalities with different NT values}

In 241 samples with NT $\geq 2.5 \mathrm{~mm}$, the detection rate of chromosomal abnormalities was $20.75 \%$ ( 50 / 241 ). The NT values of 86 cases were $2.5-2.9 \mathrm{~mm}$, the chromosome abnormality rate was $11.63 \%$ (10/86); the NT values of 73 cases were $3.0-3.4 \mathrm{~mm}$, the chromosome abnormality rate was $17.81 \%$ (13/ 73 ); the NT values of 50 cases were $3.5-4.4 \mathrm{~mm}$, the chromosome abnormality rate was $20 \%$ (10/50); the NT values of 21 cases were $4.5-5.4 \mathrm{~mm}$, the chromosome abnormality rate was $47.62 \%$ (10/21); and the NT of 11 cases was $\geq 5.5 \mathrm{~mm}$, the rate of chromosome abnormality was $63.64 \%$. In 125 cases of normal group with NT $<2.5 \mathrm{~mm}$, the rate of pathogenic chromosome abnormality was $0.8 \%(1 / 125)$. The chromosome abnormality rate of each group with NT $\geq 2.5 \mathrm{~mm}$ was different from that of the normal group, and the difference was statistically significant, and the fetal chromosome abnormality rate increased gradually with the thickening of NT (Table 1).

\section{Comparison NT thickening alone with NT thickening combined with other abnormalities}

Among the 167 cases of simple NT thickening, the rate of fetal chromosome abnormality was $13.17 \%$ (22/ 167$)$. In 74 cases of NT thickening combined with other abnormalities ( fetal nasal bone dysplasia, cervical lymphocystoma, subcutaneous tissue thickening, edema, choroid plexus cyst, single umbilical artery, ventricular hyperintense spot, elderly, adverse fertility history, etc.), the fetal chromosome abnormality rate was $35.14 \% \varangle 26 / 74 \rrbracket$,and the difference between the two groups was statistically significant ( Table 3 ).

\section{Follow-up prenatal and postnatal examination of fetuses with NT $\geq 5.0 \mathrm{~mm}$}

In 18 samples with NT $\geq 5.0 \mathrm{~mm}$, the abnormal rate of fetal chromosome was $50 \%$ (9/ 18). We also followed up the subsequent pregnancy and fetal delivery of all samples (Table 4).

\section{Discussion}

The NT value measured by $11-13+6 \mathrm{~W}$ ultrasound is an important indicator for evaluating fetal chromosomal abnormalities in the early pregnancy [13]. Studies have shown that [14], when the NT value is $3.4 \mathrm{~mm}$, the fetal chromosome abnormality rate is only $3.7 \%$ when NT $\geq 3.5 \mathrm{~mm}$, the fetal chromosome abnormality rate is as high as $21.1 \%$. In this study, among 240 samples with NT $\geq 2.5 \mathrm{~mm}$, the fetal chromosome abnormality rate was $20.75 \%$ ( $50 / 241$ ). Among them, trisomy 21 syndrome accounted for 50\% (25/50), 18 trisomy syndrome accounted for 10\% (5/ 50), Turner syndrome accounted for 10\% (5/ 50), and other chromosome abnormalities accounted for $30 \%$ (15/50). The results suggest that NT thickening is closely related to chromosome abnormalities, especially trisomy 21 syndrome. Souka et al showed that when NT $\geq 3.5 \mathrm{~mm}$, the risk of chromosome abnormality increased exponentially with the thickening of NT [14]. Maya et al reported that the fetal chromosome abnormality rates in NT $\leq 2.9 \mathrm{~mm}, 3.0-3.4 \mathrm{~mm}$ and $\geq 3.5 \mathrm{~mm}$ groups were $1.7 \%, 6.5 \%$ and $13.8 \%$ respectively [15]. In this study, the fetal chromosome abnormality rates of the six groups with NT values $<2.5 \mathrm{~mm}, 2.5-2.9 \mathrm{~mm}, 3.0-3.4 \mathrm{~mm}, 3.5-4.4 \mathrm{~mm}, 4.5-$ $5.4 \mathrm{~mm}$ and $\geq 5.5 \mathrm{~mm}$ were $0.8 \%, 11.63 \%, 17.81 \%, 20 \%, 47.62 \%$ and $63.64 \%$ respectively. The above results showed that the thicker the NT was, the higher the abnormal rate of fetal chromosome was, which is consistent with the previous literature. At present, most studies [16-18] set the cutoff value for prenatal diagnosis of NT thickening as $\geq 3.5 \mathrm{~mm}$. Maya and Lena $[15,19]$ suggest that fetuses with NT $\geq 3.0 \mathrm{~mm}$ should be evaluated for prenatal diagnosis. However, the chromosome abnormality rate of fetuses with NT value of $2.5-2.9 \mathrm{~mm}$ was $11.63 \%$ in this study, which was significantly higher than $0.8 \%$ of NT value < $2.5 \mathrm{~mm}$, and the difference was statistically significant. Therefore, more experimental data are needed to support the criteria for determining the critical value of NT thickening for prenatal diagnosis. Our results support the evaluation of invasive prenatal diagnosis in pregnant women with NT $\geq 2.5 \mathrm{~mm}$. 
The indications of interventional prenatal diagnosis include not only increased NT value, but also the elderly, adverse fertility history, abnormal ultrasound, high risk of serological screening, and chromosomal abnormalities in both husband and wife, etc [20]. In the study of XueShuya [21], the rate of chromosomal abnormalities in fetuses with simple NT thickening was $22.6 \%$, while the rate of chromosomal abnormalities combined with other ultrasound abnormalities such as lymphocystoma, nasal bone deficiency or fetal edema was $60.9 \%$. In this study, according to the different indications of prenatal diagnosis, 241 cases of NT thickening were divided into NT thickening alone and NT thickening combined with other abnormalities (fetal nasal bone dysplasia, cervical lymphocystoma, subcutaneous tissue thickening, edema, choroid plexus cyst, single umbilical artery, ventricular hyperintense spot, elderly ,adverse fertility history,etc.). The abnormal rates of fetal chromosomes were $13.17 \%$ and $35.14 \%$, respectively. The rate of fetal chromosomal abnormalities is higher when NT thickening combined with other abnormalities, so when NT thickening combined with other ultrasonic abnormalities in early pregnancy, it is more necessary to exclude chromosomal abnormalities in time for prenatal diagnosis.

At present, CMA detection is more and more used in prenatal diagnosis, and many studies have confirmed the correlation between NT thickening and chromosome microdeletion or microrepetitive variation [22, 23]. Grande et al conducted a meta-analysis of 17 studies and concluded that about $4 \%$ more pathogenic chromosome microdeletions or microrepetitive variations could be detected by CMA technology in fetuses with normal karyotype analysis [12]. Egloff et al reported that in fetuses with NT thickening in early pregnancy, CMA could detect about $2.7 \%$ of pathogenic chromosome variations that cannot be detected by conventional karyotype analysis [22]. In this study, the karyotype analysis and CMA of chromosome abnormality detection rate in 366 samples were $13.39 \%$ ( 49 / 366 ) and $13.93 \%$ ( 51 / 366 ), respectively, with no significant difference. However, CMA can bring us more data information, which can correlate genotype with phenotype,and complement each other with karyotype analysis to facilitate clinical consultation. In this study, karyotype analysis showed that 5 samples had complex chromosomal rearrangements and 1 sample had additional marker chromosomes, CMA results not only supplemented the karyotype results, suggesting that five samples had chromosome microdeletions and duplications at the same time, clarifying the source of one marker chromosome (Fig. 2), Fig. 2. $\$ was the CMA result and Fig. 2.『 was the karyotype result. CMA results but also supplemented the genotype was associated with phenotype, giving us more information. In view of the complex chromosome structure rearrangement of five samples, we verified the peripheral blood chromosomes of three samples of parents and found that two cases were new mutations and one case was caused by maternal inheritance (Fig. 1),


followed up the pregnancy: 10 cases of pathogenic CNVs (1), 7 cases were detected by karyotype analysis and CMA, and pregnant women chose induced labor after informed choice. (2) 3 cases were detected by CMA but not detected by karyotype analysis. 1 case with a 5.37Mb deletion of 9q22.32q31.1, the related phenotypes included epileptic encephalopathy, language development disorder, macrosomia, learning disability and nephroblastoma. Ultrasound also revealed multiple fetal abnormalities: cervical fold thickening, bilateral cleft lip and palate, posterior fossa cystic structure, and bilateral renal separation. The pregnant woman decided to induce labor after informed choice. 1 case with a $1.4 \mathrm{Mb}$ deletion of 17p12, whose pathogenicity was related to hereditary pressure susceptible peripheral neuropathy. The CMA of parents confirmed that it was caused by the father, and no abnormality was found in ultrasound. After careful consideration, the pregnant woman chose to continue pregnancy, and has delivered a healthy baby. 1 case with a $2.49 \mathrm{Mb}$ duplication of $22 \mathrm{q} 11.21$,the repetition in this region involves 22q11.2 microrepetition syndrome, but it is an incomplete explicit syndrome, with a penetrance rate of about $21.9 \%$. The related abnormal phenotypes include developmental retardation and mental retardation, hypodystonia, autistic behavior, congenital heart abnormalities, and so on. Considering the normal ultrasound examination and the existence of explicit insufficiency, the pregnant woman carefully chose to continue the pregnancy, and now she has given birth to a normal fetus, about 4 months old, and the cardiac ultrasound examination is normal. 2 cases of probable pathogenic CNVs (1) 1 case with a 394Kb deletion of 1q21.1, this region is the susceptible site of thrombocytopenia-radial deficiency syndrome, the main phenotypes are thrombocytopenia, bilateral radius loss, cardiac and urinary system abnormalities and so on. The syndrome follows the autosomal recessive genetic model. In addition to the single copy deletion in the region, which is a possible pathogenic CNV, gene mutations can also be found in most patients. However, ultrasound examination is normal, the pregnant women carefully choose to continue pregnancy, and now she has given birth to a normal fetus, about 2 months old, heart, urinary and other ultrasound examination is normal. (2) 1 case with a 5.09Mb deletion of 8q22.3q23.1, involving 17 OMIM genes such as ZFPM2.The mutation of ZFPM2 gene is related to cardiac abnormalities of autosomal dominant inheritance such as tetralogy of Fallot and double outlet of right ventricle. and heterozygous mutations of ZFPM2 gene can also be found in patients with partial reversal syndrome. The deletion of ZFPM2 gene can be derived from parents with normal phenotype, and the deletion is a possible pathogenic CNV.Fetal ultrasound and other tests are normal, pregnant women carefully choose to continue pregnancy, has now given birth to a normal fetus, more than 20 days, cardiac ultrasound examination is normal. 15 cases of VOUS: 1 case lost follow-up information, 14 cases of ultrasound and other examinations were normal, It is suggested that the source of Vous should be confirmed by fetal parents, but only 2 cases were verified by their parents, and the results were all caused by heredity. Pregnant women chose to continue pregnancy carefully and have given birth to healthy fetuses. Most fetuses with Vous have better pregnancy outcome, but we still need to combine ultrasound and other comprehensive assessment, and carry out long-term and detailed clinical follow-up of born babies to accumulate more clinical information.

Domenico et al showed that [24] when the NT value was 3.5-4.4mm, about 70\% of the fetuses had no obvious abnormality until delivery; when the NT value was $4.5-5.4 \mathrm{~mm}$, only $50 \%$ had no obvious abnormality; when the NT value was $5.5-6.4 \mathrm{~mm}$, only $30 \%$ had no obvious abnormality; when the NT value was $\geq$ $6.5 \mathrm{~mm}$, only $15 \%$ had no obvious abnormality. Souka et al pointed out that [14] NT thickening is not only related to chromosome abnormalities, but also with adverse perinatal outcomes caused by various fetal malformations, dysplasia, rupture and genetic syndrome. However, when chromosome problems were excluded and the fetus survived to metaphase without any abnormality in ultrasound, the risk of poor perinatal outcome and postnatal growth retardation did not increase statistically. In this paper, 18 fetuses with $\geq 5.0 \mathrm{~mm}$ were followed up. (1) 9 cases of chromosome abnormalities were detected by karyotype analysis and CMA. Pregnant women chose induced labor after informed choice. (2) in 5 cases, only early ultrasound showed thickening of NT, normal ultrasound such as anaphase aberration, normal karyotype analysis and CMA. Pregnant women chose to continue pregnancy carefully and all gave birth to normal fetuses. (3) 1 case with a $524 \mathrm{~Kb}$ accication of $3 q 29$, the meaning of repetition in this area was unknown, the parents verified that the repetition was inherited from the father with normal phenotype, and the ultrasound examination was normal, the pregnant woman carefully chose to continue the pregnancy, and now she has given birth to a normal fetus, 18 months old. (4) 1 case of early ultrasound showed that the cervical fold thickened by NT $6.1 \mathrm{~mm}$, system ultrasound showed that the thickness of cervical fold is about $9 \mathrm{~mm}$ and the other was normal, chromosome karyotype analysis and CMA were normal, and the pregnant woman chose to continue the pregnancy cautiously, and now she has given birth to a normal fetus, more than 2 years old. (5) 1 case showed 
NT8.0mm and cervical and dorsal lymphoid cystic tumor in the early stage, normal ultrasound in the middle and later stage, normal chromosome karyotype analysis and CMA. The pregnant woman carefully chose to continue the pregnancy, and now she has given birth to a normal fetus for more than 7 months. (6) 1 case of early ultrasound revealed NT $5.0 \mathrm{~mm}$ and local skin edema of the chest and abdominal wall of the fetus. In the second trimester, the width of bilateral ventricles of the fetus was about $9 \mathrm{~mm}$, chromosome karyotype analysis and CMA detection were normal, and the width of the left ventricle of the fetus in the late pregnancy was about $9 \mathrm{~mm}$. Noonan and other syndromes were ruled out by gene detection in the whole exon group. The pregnant woman chose carefully to continue the pregnancy, and now she has given birth to a normal fetus for more than 3 months. Among the 18 fetuses, 9 fetuses had normal chromosomes and no obvious abnormalities in ultrasound, and all of them had a good pregnancy outcome. Therefore, even if the NT is thickened, the fetus usually has a better pregnancy outcome when there are no obvious abnormalities in chromosome, whole exon gene detection and middle and late ultrasound, which should be treated with caution.

\section{Conclusions}

In summary, with the thickening of NT, especially when combined with other abnormalities, the rate of fetal chromosome abnormalities gradually increased. Therefore, invasive prenatal diagnosis should be performed for pregnant women with NT $\geq 2.5 \mathrm{~mm}$, and chromosome karyotype analysis and CMA detection should be combined to supplement each other for prenatal genetic counseling. However, even if the NT is thickened, we need to be cautious. After excluding chromosome, whole exon gene detection and ultrasound abnormalities, the fetus usually has a better pregnancy outcome.

\section{Declarations}

\section{Ethics approval and consent to participate}

The study was approved by the Hospital Ethics Committee of Anhui Maternity and Child Health Care Hospital. Each patient signed informed consent prior to study enrollment.

\section{Consent for publication}

Not applicable.

\section{Availability of data and materials}

The data supporting the conclusions of this article is included within the article.

\section{Funding}

This work was supported by the Anhui Key Research and Development Program (NO: 202004j07020004).

\section{Acknowledgments}

We would like to thank our patients for agreeing to donate their personal data to our study and have these been published. We are also grateful to the technical support of doctors and paramedic staff of Maternity and Child Health Hospital, Hefei, Anhui, PR China.

\section{Authors' contributions}

All authors have participated in the study and manuscript preparation.

\section{Conflict of interest}

The authors have declared no conflicts of interest.

\section{References}

1. Shamshirsaz AA, Salmanian B, Ravangard SF, et al. Nuchal translucency and cardiac abnormalities in euploid singleton pregnancies. J Matern Fetal Neonatal Med. 2014;27(5):495-9.

2. Sotiriadis A, Papatheodorou S, Makrydimas G. Neurodevelopmental outcome of fetuses with increased nuchal translucency and apparently normal prenatal and/or postnatal assessment: a systematic review. Ultrasound Obstet Gynecol. 2012;39(1):10-9.

3. Wright D, Kagan KO, Molina FS, et al. A mixture model of nuchal translucency thickness in screening for chromosomal defects. Ultrasound Obstet Gynecol. 2008;31(4):376-83.

4. Alamillo CM, Fiddler M, Pergament E. Increased nuchal translucency in the presence of normal chromosomes: what's next? Curr Opin Obstet Gynecol. 2012;24(2):102-8.

5. Xue Shuya,Chen Jingsi,Zhang Huimin,et al.Correlation between increased translucency and chromosomal abnormalities.Journal of Practical Obstetrics and Gynecology 2019;35(5): 382-384.

6. Neiger R. First Trimester Ultrasound in Prenatal Diagnosis-Part of the Turning Pyramid of Prenatal Care. J Clin Med. 2014;3(3):986-96. Published 2014;Sep 5. 
7. Lund IC, Christensen R, Petersen OB, et al. Chromosomal microarray in fetuses with increased nuchal translucency. Ultrasound Obstet Gynecol. 2015;45(1):95-100.

8. Hillman SC, McMullan DJ, Hall G, et al. Use of prenatal chromosomal microarray: prospective cohort study and systematic review and meta-analysis. Ultrasound Obstet Gynecol. 2013;41(6):610-20.

9. Grande M, Jansen FA, Blumenfeld YJ, et al. Genomic microarray in fetuses with increased nuchal translucency and normal karyotype: a systematic review and meta-analysis. Ultrasound Obstet Gynecol. 2015;46(6):650-8.

10. Armour CM, Dougan SD, Brock JA, et al. Practice guideline: joint CCMG-SOGC recommendations for the use of chromosomal microarray analysis for prenatal diagnosis and assessment of fetal loss in Canada. J Med Genet. 2018;55(4):215-21.

11. Breman A, Pursley AN, Hixson P, et al. Prenatal chromosomal microarray analysis in a diagnostic laboratory; experience with $>1000$ cases and review of the literature. Prenat Diagn. 2012;32(4):351-61.

12. Grande M, Jansen FA, Blumenfeld YJ, et al. Genomic microarray in fetuses with increased nuchal translucency and normal karyotype: a systematic review and meta-analysis. Ultrasound Obstet Gynecol. 2015;46(6):650-8.

13. Xinrong Zhao,Li Gao,Yi Wu,et al.Application of chromosomal microarray in fetuses with increased nuchal translucency.Maternal Fetal \& Neonatal Medicine.2019;27(1):1-6.

14. Souka AP, Von Kaisenberg CS, Hyett JA,et al. Increased nuchal translucency with normal karyotype. Am J Obstet Gynecol. 2005;192(4):1005-21.

15. Maya I, Yacobson S, Kahana S,et al. Cut-off value of nuchal traslucency as indication for chromosomal microarray analysis[J]. Ultrasound Obstet Gynecol. 2017;50(3):332-5.

16. Bakker M. Pajkrt E,Bilardo CM.Increased nuchal traslucency with normal karyotype and anomaly scan:What next?Best. Pract Res Clin Obstet Gynaecol. 2014;28:355-66.

17. Lund IC, Christensen R, Petersen OB,et al. Chromosomal microarray in fetuses with increased nuchal translucency. Ultrasound Obstet Gynecol. 2015;45(1):95-100.

18. Oneda B, Baldinger R, Reissmann R, et al. High-resolution chromosomal microarrays in prenatal diagnosis significantly increase diagnostic power. Prenat Diagn. 2014;34(6):525-33.

19. Lena Sagi-Dain,Amihood Singer,Idit Maya.Microarray testing in pregnancies with nuchal translucency 3-3.4mm-time to change the cut-off.Ultrasound and Genetics.2020;8(3):77-84.

20. Chen YP, Xu F, Tang SH,et al. Cytogenetic analysis of amniotic fluid on 4943 high-risk pregnant women[J]. Wenzhou Med Univ. 2019;49(10):756-9.

21. Xue Shuya,Chen Jingsi,Zhang Huimin,et al.Correlation between increased nuchal translucency and chromosomal abnormalities[J].Practical Obstetrics and Gynecology.2019;35(5):382-385.

22. Egloff M, Hervé B, Quibel T, et al. Diagnostic yield of chromosomal microarray analysis in fetuses with isolated increased nuchal translucency: a French multicenter study. Ultrasound Obstet Gynecol. 2018;52(6):715-21.

23. Su L, Huang H, An G, et al. Clinical application of chromosomal microarray analysis in fetuses with increased nuchal translucency and normal karyotype. Mol Genet Genomic Med. 2019;7(8):e811.

24. De Domenico R, Faraci M, Hyseni E, et al. Increased nuchal traslucency in normal karyotype fetuses. J Prenat Med. 2011;5(2):23-6.

\section{Tables}

Table 1. Distribution of chromosomal abnormalities detected by karyotype and chromosomal microarray analysis(CMA).

\begin{tabular}{|c|c|c|c|c|c|c|c|c|c|c|c|c|c|}
\hline \multirow[b]{2}{*}{$\mathrm{NT}(\mathrm{mm})$} & \multirow[b]{2}{*}{$N(\%)$} & \multicolumn{6}{|c|}{ karyotype } & \multicolumn{5}{|l|}{ CMA } & \multirow[b]{2}{*}{ isolation rate } \\
\hline & & $\begin{array}{l}\text { Trisomy } \\
21\end{array}$ & $\begin{array}{l}\text { Trisomy } \\
18\end{array}$ & $\begin{array}{l}\text { Trisomy } \\
13\end{array}$ & $45, X$ & Others & Total & $\begin{array}{l}\text { pathogenic } \\
\text { CNVs }\end{array}$ & $\begin{array}{l}\text { likely } \\
\text { pathogenic } \\
\text { CNVs }\end{array}$ & vous & aneuploid & Total & \\
\hline$<2.5$ & 125 & 0 & 0 & 0 & 0 & 2 & 2 & 0 & 0 & 4 & 1 & 5 & $0.8(1 / 125)$ \\
\hline $2.5-2.9$ & 86 & 4 & 0 & 0 & 0 & 6 & 10 & 3 & 1 & 6 & 7 & 17 & $11.63(10 / 86)$ \\
\hline $3.0-3.4$ & 73 & 5 & 2 & 0 & 1 & 3 & 11 & 4 & 0 & 3 & 9 & 16 & $17.81(13 / 73)$ \\
\hline $3.5-4.4$ & 50 & 4 & 2 & 0 & 3 & 0 & 9 & 1 & 1 & 1 & 9 & 12 & $20(10 / 50)$ \\
\hline $4.5-5.4$ & 21 & 8 & 0 & 0 & 0 & 2 & 10 & 1 & 0 & 0 & 9 & 10 & $47.62(10 / 21)$ \\
\hline$\geq 5.5$ & 11 & 4 & 1 & 0 & 1 & 1 & 7 & 1 & 0 & 1 & 6 & 8 & $63.64(7 / 11)$ \\
\hline Total & 366 & 25 & 5 & 0 & 5 & 14 & 49 & 10 & 2 & 15 & 41 & 68 & \\
\hline
\end{tabular}

Table 2. Classification of CNV and pregnancy outcome 


\begin{tabular}{|c|c|c|c|c|c|c|}
\hline Case & $\mathrm{NT}(\mathrm{mm})$ & CMA result & $\begin{array}{l}\text { Size and type of } \\
\text { CNV }\end{array}$ & $\begin{array}{l}\text { Genes affected } \\
\text { /syndromes }\end{array}$ & Categorization & $\begin{array}{l}\text { Pregnancy } \\
\text { outcome }\end{array}$ \\
\hline 1 & 3.0 & $\begin{array}{l}\text { arr } 4 q 35.1 q 35.2(186,167,916- \\
187,842,570) \times 3\end{array}$ & $1.67 \mathrm{Mb}$ dup & 10 OMIM genes & VOUS & Unknown \\
\hline 2 & 3.3 & $\begin{array}{l}\text { arr 7q31.31q36.3(120,072,971- } \\
\text { 159,119,707)x3, } \\
\text { 18p11.32p11.31(136,227-3,251,461)x1 }\end{array}$ & $\begin{array}{l}39.03 \mathrm{Mb} \text { dup, } \\
3.11 \mathrm{Mb} \text { del }\end{array}$ & 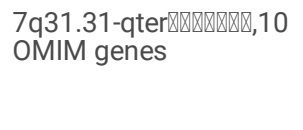 & $\begin{array}{l}\text { Pathogenic, } \\
\text { Vous }\end{array}$ & $\begin{array}{l}\text { Give up, induce } \\
\text { labor }\end{array}$ \\
\hline 3 & 6.4 & $\begin{array}{l}\text { arr 18p11.32p11.23(136,227- } \\
\text { 7,216,195)x1, } \\
\quad 18 \mathrm{q} 11.2 \mathrm{q} 23(24,858,577-78,013,728) \times 3\end{array}$ & $\begin{array}{l}\text { 7.08Mb del, } \\
53.15 \mathrm{Mb} \text { dup }\end{array}$ &  & $\begin{array}{l}\text { Pathogenic, } \\
\text { Pathogenic, }\end{array}$ & $\begin{array}{l}\text { Give up, induce } \\
\text { labor }\end{array}$ \\
\hline 4 & 2.9 & $\begin{array}{l}\text { arr 10p15.3(100,047-1,745,277)x4, } \\
\text { 10p12.1p11.1(24,914,898- } \\
39,030,508) \times 2-3\end{array}$ & $\begin{array}{l}\text { 1.64Mb dup, } \\
\text { 14.11Mb } \\
\text { dup(mosaic) }\end{array}$ & $\begin{array}{l}10 \text { OMIM genes, } \\
43 \text { OMIM genes }\end{array}$ & $\begin{array}{l}\text { VOUS, } \\
\text { Pathogenic }\end{array}$ & $\begin{array}{l}\text { Give up, induce } \\
\text { labor }\end{array}$ \\
\hline 5 & 3.1 & $\begin{array}{l}\text { arr 2q37.3(239,198,046-242,782,258)x1, } \\
18 q 21.1 q 23(44,353,417-78,013,728) \times 3\end{array}$ & $\begin{array}{l}\text { 3.58Mb del, } \\
33.66 \mathrm{Mb} \text { dup }\end{array}$ &  & $\begin{array}{l}\text { Pathogenic, } \\
\text { Pathogenic }\end{array}$ & $\begin{array}{l}\text { Give up, induce } \\
\text { labor }\end{array}$ \\
\hline 6 & 5.5 & arr 3q29(196,862,001-197,386,180)x3 & $524 \mathrm{~Kb}$ dup & 2 OMIM genes & vous & $\begin{array}{l}\text { Delivery, } \\
\text { normal }\end{array}$ \\
\hline 7 & 2.8 & $\begin{array}{l}\text { arr 15q13.2q13.3(31,098,690- } \\
32,915,723) \times 3\end{array}$ & $1.81 \mathrm{Mb}$ dup & 7 OMIM genes & VOUS & $\begin{array}{l}\text { Delivery, } \\
\text { normal }\end{array}$ \\
\hline 8 & 3.0 & arr $17 \mathrm{p} 12(14,083,054-15,482,833) \times 1$ & $1.4 \mathrm{Mb}$ del & 5 OMIM genes & Pathogenic & \\
\hline 9 & 2.7 & arr 9p23(9,914,588-10,133,062)x1 & $218 \mathrm{~Kb}$ del & 1 OMIM genes & Vous & $\begin{array}{l}\text { Delivery, } \\
\text { normal }\end{array}$ \\
\hline 10 & 3.1 & $\begin{array}{l}\text { arr 11q22.3(104,708,299- } \\
105,459,967) \times 3\end{array}$ & $752 \mathrm{~Kb}$ dup & 7 OMIM genes & VOUS & $\begin{array}{l}\text { Delivery, } \\
\text { normal }\end{array}$ \\
\hline 11 & 2.8 & arr 1p13.2(112,802,599-113,868,278)x3 & $1.06 \mathrm{Mb}$ dup & 8 OMIM genes & VOUS & $\begin{array}{l}\text { Delivery, } \\
\text { normal }\end{array}$ \\
\hline 12 & 2.5 & $\begin{array}{l}\text { arr 11p14.2p12(26,154,097- } \\
40,951,082) \times 1\end{array}$ & $14.79 \mathrm{Mb}$ del & WAGRIII & Pathogenic & $\begin{array}{l}\text { Give up, induce } \\
\text { labor }\end{array}$ \\
\hline 13 & 3.2 & arr 8p22(15,258,183-15,968,982)x3 & $711 \mathrm{~Kb}$ dup & 2 OMIM genes & VOUS & $\begin{array}{l}\text { Delivery, } \\
\text { normal }\end{array}$ \\
\hline 14 & 2.9 & arr 2q37.3(241,490,065-242,782,258)x1 & $1.29 \mathrm{Mb}$ del & 25 OMIM genes & VOUS & $\begin{array}{l}\text { Delivery, } \\
\text { normal }\end{array}$ \\
\hline 15 & 3.9 & arr $6 q 12(65,196,218-65,743,530) \times 1$ & $547 \mathrm{~Kb}$ del & 1 OMIM genes & VOUS & $\begin{array}{l}\text { Delivery, } \\
\text { normal }\end{array}$ \\
\hline 16 & 3.3 & arr 22q11.21(18,970,561-21,461,017)x3 & $2.49 \mathrm{Mb}$ dup & 22q11.2पराप्या & $\begin{array}{l}\text { Pathogenic } \\
\text { (nonpenetrance) }\end{array}$ & $\begin{array}{l}\text { Delivery, } \\
\text { normal }\end{array}$ \\
\hline 17 & 5.2 & $\begin{array}{l}\text { arr 5p15.33p15.31(113,576- } \\
9,149,369) \times 1 \\
5 p 15.31 q 11.1(9,153,500-49,475,697) \times 3\end{array}$ & $\begin{array}{l}9.03 \mathrm{Mb} \text { del, } \\
40.32 \mathrm{Mb} \text { dup }\end{array}$ & 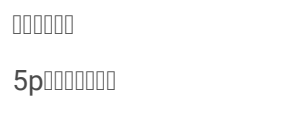 & $\begin{array}{l}\text { Pathogenic, } \\
\text { Pathogenic }\end{array}$ & $\begin{array}{l}\text { Give up, induce } \\
\text { labor }\end{array}$ \\
\hline 18 & 2.5 & $\begin{array}{l}\text { arr 9p24.3p23(208,454-9,085,530)x1, } \\
\text { 13q31.1q34(87,397,574_115,107,733)x3 }\end{array}$ & $\begin{array}{l}\text { 8.87Mb del, } \\
27.71 \mathrm{Mb} \text { dup }\end{array}$ & $\begin{array}{l}34 \text { OMIM genes, } \\
78 \text { OMIM genes }\end{array}$ & $\begin{array}{l}\text { Pathogenic, } \\
\text { Pathogenic }\end{array}$ & $\begin{array}{l}\text { Give up, induce } \\
\text { labor }\end{array}$ \\
\hline 19 & 2.8 & $\begin{array}{l}\text { arr 12p11.21p11.1(32,407,341- } \\
34,897,417) \times 3 \\
12 q 11 q 12(37,856,237-42,720,825) \times 3\end{array}$ & $\begin{array}{l}2.49 \mathrm{Mb} \text { dup, } \\
4.86 \mathrm{Mb} \text { dup }\end{array}$ & $\begin{array}{l}7 \text { OMIM genes, } \\
11 \text { OMIM genes }\end{array}$ & $\begin{array}{l}\text { vous, } \\
\text { vous }\end{array}$ & $\begin{array}{l}\text { Delivery, } \\
\text { normal }\end{array}$ \\
\hline 20 & 2.7 & arr 1q21.1(145,382,123-145,775,966)x1 & $394 \mathrm{~Kb}$ del & 14 OMIM genes & likely pathogenic & $\begin{array}{l}\text { Delivery, } \\
\text { normal }\end{array}$ \\
\hline 21 & 4.4 & $\begin{array}{l}\text { arr 8q22.3q23.1(103,348,066- } \\
108,445,788) \times 1\end{array}$ & $5.09 \mathrm{Mb}$ del & 17 OMIM genes & likely pathogenic & $\begin{array}{l}\text { Delivery, } \\
\text { normal }\end{array}$ \\
\hline 22 & 2.9 & arr 22q11.21(20,716,876-21,464,764)x3 & $748 \mathrm{~Kb}$ dup & 12 OMIM genes & vous & $\begin{array}{l}\text { Delivery, } \\
\text { normal }\end{array}$ \\
\hline 23 & 2.3 & arr 7q36.1(151,839,233-151,956,096)x3 & $117 \mathrm{~Kb}$ dup & 1 OMIM genes & vous & $\begin{array}{l}\text { Delivery, } \\
\text { normal }\end{array}$ \\
\hline 24 & 1.2 & arr 4q21.3(87,065,802-87,601,097)x4 & $535 \mathrm{~Kb}$ dup & 2 OMIM genes & Vous & $\begin{array}{l}\text { Delivery, } \\
\text { normal }\end{array}$ \\
\hline 25 & 0.9 & arr $6 p 25.2(2,662,677-3,266,323) \times 3$ & $604 \mathrm{~Kb}$ dup & 10 OMIM genes & vous & Delivery, \\
\hline
\end{tabular}




\begin{tabular}{|c|c|c|c|c|c|c|}
\hline & & & & & & normal \\
\hline 26 & 1.4 & arr $18 q 12.3(39,280,178-40,567,434) \times 1$ & $1.28 \mathrm{Mb}$ del & 2 OMIM genes & vous & $\begin{array}{l}\text { Delivery, } \\
\text { normal }\end{array}$ \\
\hline 27 & 4.4 & $\begin{array}{l}\text { Arr9q22.32q31.1(97,430,110- } \\
102,801,381) \times 1\end{array}$ & $5.37 \mathrm{Mb}$ del & 32 OMIM genes & Pathogenic & $\begin{array}{l}\text { Give up, induce } \\
\text { labor }\end{array}$ \\
\hline
\end{tabular}

Table 3. The percentages of abnormal karyotype in each groups with different indicaions

\begin{tabular}{|c|c|c|c|c|c|}
\hline \multirow[t]{2}{*}{ Indication } & \multirow[t]{2}{*}{ Number》n囚 } & \multicolumn{2}{|c|}{ karyotypic abnormality } & \multirow[t]{2}{*}{$X$ value } & \multirow[t]{2}{*}{$P$ value } \\
\hline & & Number $\ \mathrm{n} \rrbracket$ & Percentage $\varangle \% \rrbracket$ & & \\
\hline Nt thickening & 167 & 22 & $13.17 \%$ & & \\
\hline $\mathrm{Nt}$ thickening +other & 74 & 26 & $35.14 \%$ & 15.506 & 0.001 \\
\hline
\end{tabular}

Table 4. Karyotype, CMA results and pregnancy outcome of fetuses with NT $\geq 5.0 \mathrm{~mm}$

\begin{tabular}{|c|c|c|c|c|}
\hline Case & $\mathrm{NT}(\mathrm{mm})$ & CMA & Karyotype & Pregnancy outcome \\
\hline 1 & 9.4 & arr Xp22.33q28(168,551-155,233,098)x1 & $45, X$ & Give up, induce labor \\
\hline 2 & 6.1 & $\operatorname{arr}(1-22) \times 2,(X N) \times 1$ & $46, X Y$ & Delivery, normal \\
\hline 3 & 6.4 & $\begin{array}{l}\text { arr 18p11.32p11.23(136,227-7,216,195)x1, } \\
\text { 18q11.2q23(24,858,577-78,013,728)x3 }\end{array}$ & $46, \mathrm{XX}, \mathrm{add}(18)(\mathrm{p} 11.2)$ & Give up, induce labor \\
\hline 4 & 5.5 & arr 21q11.2q22.3(15016486-48093361)×3 & $47, X X,+21$ & Give up, induce labor \\
\hline 5 & 6.6 & arr 18p11.32q23(136227_78013728)x3 & $47, X Y,+18$ & Give up, induce labor \\
\hline 6 & 7 & $\operatorname{arr}(1-22) \star 2,(X N) \star 1$ & $46, X X$ & Delivery, normal \\
\hline 7 & 5.5 & arr 3q29(196,862,001-197,386,180)x3 & $46, X Y$ & Delivery, normal \\
\hline 8 & 8.0 & arr 21q11.2q22.3(15,016,486-48,093,361)x3 & $47, X Y,+21$ & Give up, induce labor \\
\hline 9 & 9.2 & arr 21q11.2q22.3(15,016,486-48,093,361)x3 & $47, X X,+21$ & Give up, induce labor \\
\hline 10 & 8.0 & $\operatorname{arr}(1-22) \star 2,(X N) \star 1$ & $46, X X$ & Delivery, normal \\
\hline 11 & 5.4 & $\operatorname{arr}(1-22) \star 2,(X N) \star 1$ & $46, X Y$ & Delivery, normal \\
\hline 12 & 5.4 & $\operatorname{arr}(1-22) \star 2,(\mathrm{XN}) \star 1$ & $46, X Y$ & Delivery, normal \\
\hline 13 & 7.8 & arr 21q11.2q22.3(15,016,486-48,093,361)x3 & $47, X Y,+21$ & Give up, induce labor \\
\hline 14 & 5.4 & $\begin{array}{l}\text { arr 5p15.33p15.31(113576_9149369)x1; } \\
\text { 5p15.31q11.1(9153500_49475697)x3 }\end{array}$ & $46, \mathrm{XY}, \operatorname{add}(5)(\mathrm{p} 15.3)$ & Give up, induce labor \\
\hline 15 & 5.2 & arr 21q11.2q22.3(15,016,486-48,093,361)x3 & $47, X Y,+21$ & Give up, induce labor \\
\hline 16 & 5.2 & $\operatorname{arr}(1-22) \star 2,(X N) * 1$ & $46, X Y$ & Delivery, normal \\
\hline 17 & 5.1 & $\operatorname{arr}(1-22) \star 2,(X N) * 1$ & $46, X X$ & Delivery, normal \\
\hline 18 & 5.0 & $\operatorname{arr}(1-22) \star 2,(X N) \star 1$ & $46, X Y$ & Delivery, normal \\
\hline
\end{tabular}

\section{Figures}



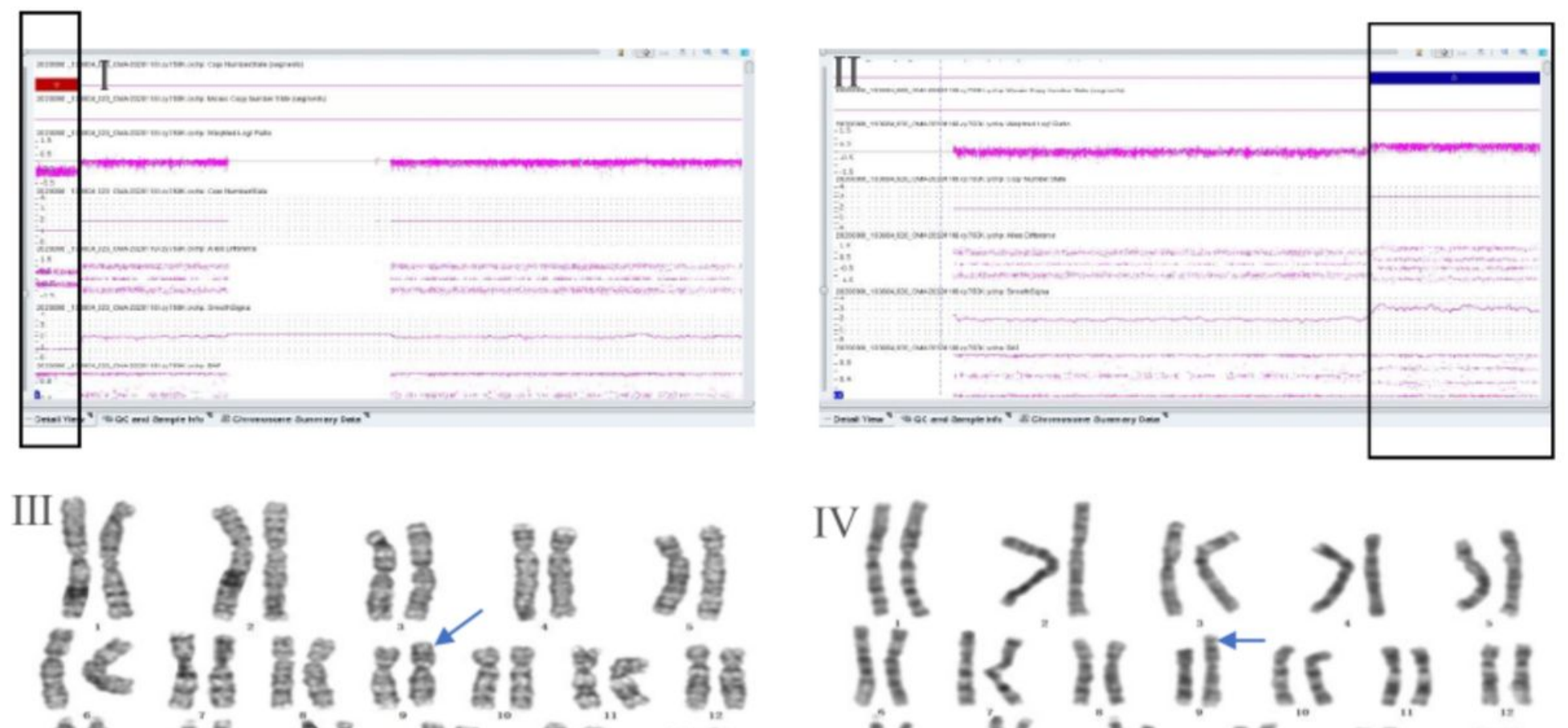



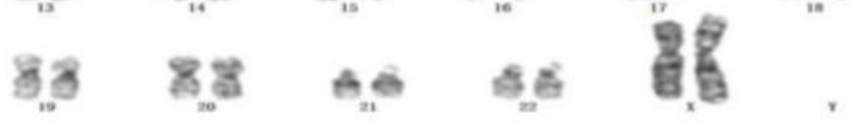

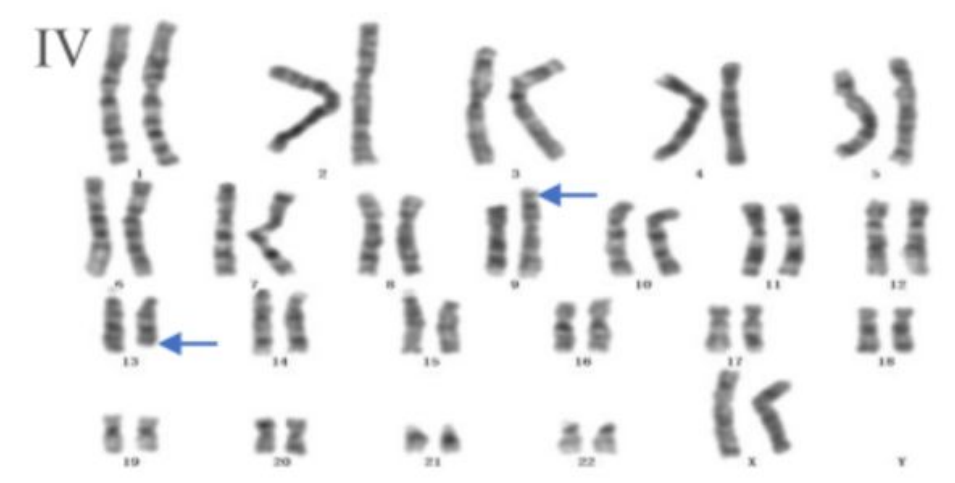

Figure 1

A case with chromosome microdeletion and microduplication
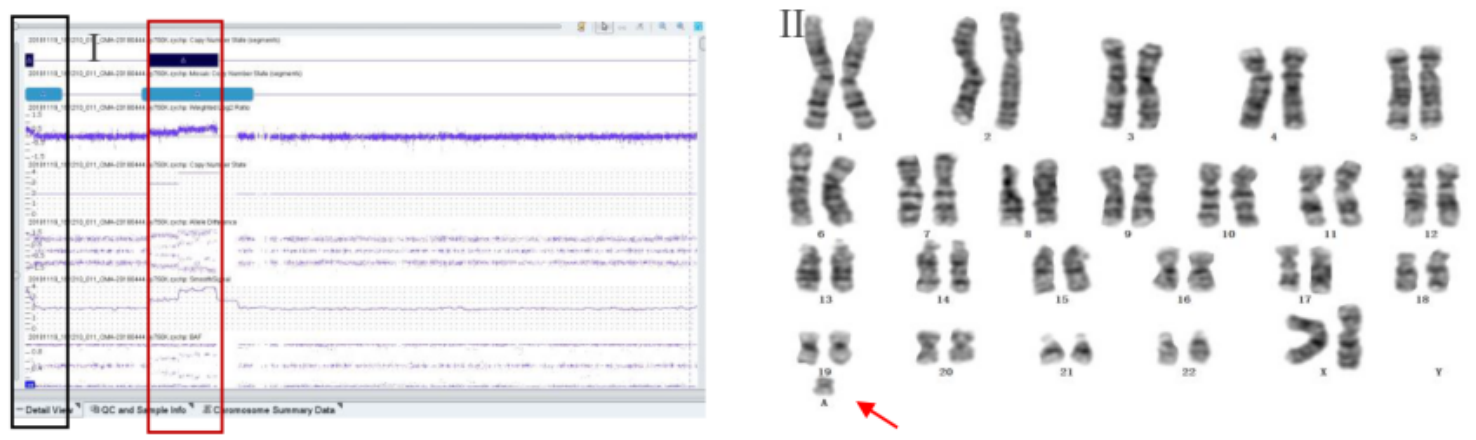

Figure 2

A case with marker chromosome 